\section{Seven months on}

Alastair Hay updates developments since the Seveso disaster in northern Italy last year

Seven months after the explosion in the trichlorophenol reacitor at Seveso which resulted in the release of tetrachlorodibenzo- $p$-dioxin (dioxin), more details of its consequences are becoming apparent. The large number of organisations involved in assessing damage and formulating policy for decontamination of the area has prevented a crash programme. There has, however, been considerable agreement as to a general plan of action-a 'cleanup' operation to try to remedy damage, the full extent of which is still unknown.

According to $\mathrm{Mr}$ Alex Rice of Cremer and Warner-the British firm of consulting chemical engineers acting as 'technical auditors' of the decontamination programme-the work of removing dioxin

"is proceeding, and there will be a high degree of reclamation of property and land in a reasonable period of time. The nature of the discharge of the reactor contents resulted in a differential degree of dioxin contamination in different areas. It has been necessary, therefore, to arrive at a graded response to solve the problem of decontamination.

At the moment, in the most severely contaminated area designated as 'Zone $A^{\prime}$, hard surfaces are being cleaned and it is hoped that some $80 \%$ of the residents evacuated from the area will be able to return to their homes in a few months. Meanwhile, in 'Zone B', less severely affected by dioxin and where inhabitants have been able to remain in their homes, vegetation in certain selected areas is being cut down and incinerated".

From the evidence available at Seveso, Cremer \& Wanner estimate that $2.5-3 \mathrm{~kg}$ of dioxin was released in the reactor discharge. On this basis and through information obtained from a model simulating the explosive reaction at the ICMESA chemical plant, they suggest that only a few hundred grams of dioxin was actually deposited on vegetation and oiher surfiaces. They maintain that the majority of dioxin was too finelly dispersed and in a particulate form too small to permit precipitation to occur, with the result that thermal air currents cannied the matenial high into the atmosphere. Conditions on the day of the explosion were ideal for the photochemical decomposition of dioxin at these altitudes, but there is no evidence to substantiate that such a degradative process actually occurred.

Earlier reports suggested that the dioxin was percolating through the soil at Seveso more quickly than recorded on previous occasions in different localities. More necent investigations, however, confirm that $98 \%$ of the dioxin is strongly adsorbed on the top $4 \mathrm{~cm}$ of soil. Some of the methods of soil sampling in the earlier stages of the decontamination programme were not rigorous enough to exclude contamination of lower layers by material on the soil surface. The later investigations confirm previous reports in the literature that dioxin is relatively immobile in soirl.

The question of the teratogenic propenties of dioxin is still causing considerable anxiety to women in Seveso. The Lombardy regional government ruled last August that pregnant women from the contaminated zones around Seveso could have legal abortions, but local doctors have in many instances consistentily refused to terminate pregnancies, and only a small proportion of pregnant women from Seveso have had abortions in Italy. The foetuses from these women are currently being examined for any signs of abnormalities and the results of the investigations should be available by March.

The reluctance of the Italian doctors to perform abontions has forced many Seveso women to seek a termination in other countries. It is doubtful whether any of the foetuses from these abontions will be examined for malformations. Doctors in Britain have voiced their concern over this loss of potentially valuable information on human teratology. They argue that there should be some agreed international code of practice on the matter to prevent it recurring and add that in Britain in particular there are arrangements to facilitate abortions and examination of the aborted foetuses for signs of abnormalitties.

In the next few months women from Seveso who were in the first trimester of pregnancy in July last year will reach full term. The children born to them and to the mothers who conceived after the explosion are those most at risk from the teratogenic properties of dioxin. It is proving an agonising time for these mothers as no one can reassune them that their 'dioxin children', as they are known locally, will be unaffected. For them, as for all the people of Seveso, centain reassurances are impossible; it is just a matter of waiting. - A report in the Turin paper La Stampa this week says that many children at a school in the Seveso area are suffering from skin rashes.
IN BRIEF

\section{European energy policy moves}

Several important aspects of European energy policy were discussed in talks in London last week between $\mathrm{Mr}$ Anthony Wedgwood Benn, the UK Energy Minister, and his West German and Dutch counterparts. The meeting was part of a series Mr Benn is having as chairman of the EEC Council of Energy Ministers.

The ministers agreed that an early decision was needed on the question of increasing the uranium enrichment capacity of Urenco, the consortium established by the three countries which is facing problems because of Dutch concern about Germany's controversial nuclear deal with Brazil. The ministers also tacitly confirmed that the European Community fusion project, JET, was far from dead by agreeing that an early decision on its siting was needed.

No official comment was available from the UK Department of Energy on an appeal last week from the EEC Energy and Research Commissioner, Guido Brunner, who urged Britain to drop its opposition to a Euratom loans plan and its insistence on a minimum safeguard price for oil. These issues could become politically connected with the JET issue.

Brunner also appealed to the USA and Canada to maintain nuclear fuel supplies to the Community, and detailed the Community's efforts in reactor safety and nuclear export controls. A Community team of experts is shortly to visit Washington to discuss these matters.

\section{UK mercury report}

"Reassuring" is the word coming from the UK Department of the Environment (DoE) on the environmental impact of mercury in Britain. A report released last week (Environmental Mercury and Man, HMSO, £1.40) is the department's tenth pollution paper, and the product of an interdepartmental working group on heavy metals.

The average person in the UK, it says, is "at no discernible risk" from exposure to mercury, but for environmental and health reasons a comprehensive knowledge of the concentration and distribution of mercury must be developed and the toxicology of mercury understood. The report says more research is needed on both the conversion of mercury to and from methylmercury compounds and the environmental pathways of mercury across the water-sediment interface in the aquatic environment; research on the mechanisms of its toxic action and on low level exposure to it over long periods is also necessary. 